\title{
Functional Changes of the Small Intestine in Over- and Undernourished Suckling Rats Support the Development of Obesity Risk on a High-Energy Diet in Later Life
}

\author{
Š. MOZEŠ, Z. ŠEFČÍKOVÁ, L'. LENHARDT ${ }^{1}$ \\ Institute of Animal Physiology, Slovak Academy of Sciences, and ${ }^{1}$ Department of Pathology, \\ University of Veterinary Medicine, Košice, Slovak Republic
}

Received January 25, 2006

Accepted March 10, 2006

On-line available March 23, 2006

\begin{abstract}
Summary
To investigate the relationship between early nutritional experience, ontogeny of the small intestinal functions and predisposition to obesity development, the following experimental models of male Sprague-Dawley rats were used: 1) rats in which the quantity of nutrition was manipulated from birth to weaning (day 30) by adjusting the number of pups in the nest to 4 (SL), 10 (NL) and 16 pups (LL) and 2) littermates of SL, NL and LL rats fed either a standard or a hypercaloric diet from days 80 to 135 of age. The overfed SL pups were overweight after day 15 and became permanently obese, whereas the underfed smaller LL pups, due to accelerated growth and enhanced food intake from day 30 to day 35, attained a body fat level that did not differ from normally fed NL rats. Moreover, a significantly increased duodenal and jejunal alkaline phosphatase (AP) activity was found in SL and LL rats and these acquired somatic and intestinal characteristics persisted from weaning throughout life. Eight weeks of high-energy diet feeding elicited a similar pattern of intestinal response in SL and LL rats that was clearly different from NL rats. Despite energy overconsumption in these three groups, both SL and LL rats still displayed enhanced AP activity and showed a significant increase in protein/DNA ratio accompanied with a significant body fat accretion. These results indicate that the postnatally acquired small intestinal changes induced by over- and undernutrition could be involved in the similar predisposition to obesity risk in later life when caloric density of the diet is raised.
\end{abstract}

Key words

Postnatal nutrition $\bullet$ Intestinal ontogeny $\bullet$ Hypercaloric diet $\bullet$ Intestinal functionality $\bullet$ Obesity risk

\section{Introduction}

Obesity represents an important public health problem worldwide. While the sedentary behavior and overeating in adult life are important factors increasing the incidence of obesity (Stubbs et al. 2004), the growing evidence from epidemiological studies suggests that both infant overnutrition (Kalies et al. 2005) and childhood undernutrition (Armstrong et al. 2003, Kain et al. 2003) may play a key role in the development of obesity risk in adolescents and adults. A coexistence of both dietary factors in the etiology of obesity has also been confirmed in experimental studies. Rats nursed in small nests (4 pups) or those born to dams fed on a high fat diet 
during gestation and the lactation period displayed metabolic and hormonal disturbances (Fiorotto et al. 1991, Plagemann et al.1999, Kozak et al. 2005) and many of these syndrome X-like alterations (hyperphagia, overweight, elevated triglycerides, obesity) persisted till the adult age (Plagemann et al. 1992, Mozeš et al. 2004). Similarly, undernutrition imposed during fetal growth and neonatal period (food/energy restriction of rat dams during both gestation and lactation or during lactation alone) lead to a later development of neuroendocrine disturbances in their progeny (Teixeira et al. 2002, Leonhardt et al. 2003, Passos et al. 2004). Moreover, these abnormalities were accelerated by the feeding of a high-fat/high-energy diet in adult age (Vickers et al. 2000, 2003).

The gastrointestinal tract and the physiological processes of digestion may also be a significant factor involved in obesity since the limitation of both energy intake and its intestinal absorption is one tool in the treatment of overweight and obesity. One of the enzymes of the small intestine is alkaline phosphatase (AP) present mainly in the microvillous zone of absorption cells of the intestinal villus, where it participates in the active capture and transport of lipids. In mature rats, the brush-borderbound AP activity increases after eating fat (Zhang et al. 1996, Mahmood et al. 2003) and several studies also revealed that long-lasting exposure to high fat diets resulted in biochemical and functional alterations of the small intestine. Feeding a high-fat diet produced an increase of mucosal protein/DNA ratio (mucosal hypertrophy), changed the brush-border membrane lipid composition and increased AP activity (Estornell et al. 1995, Kaur et al. 1996, Ghafoorunissa 2001).

The intensive growth of pups after birth coincides with the increase in length, thickness and weight and AP activity of the small intestine (Yeh et al. 1994). By day 15, the rat intestine is exclusively exposed to milk and nutritional factors such as milk lipid composition substantially influence the normal development of the gastrointestinal tract. Accordingly, milk fat concentration, energy density and milk availability for pups were decreased in dams nursing expanded litters (16 pups) (14) and increased in dams nursing four pups (Fiorotto et al. 1991, Mozeš et al. 2004). They were also reflected in a decreased alkaline phosphatase in underfed and fasted rats before weaning (Pathak et al. 1981, Hodin et al. 1995) and resulted in a permanent elevation of small intestinal AP activity in postnatally overfed small-litter rats, maintained even on standard laboratory diet after weaning (Mozeš et al. 2004). These acquired intestinal differences, however, have not been sufficiently characterized from the viewpoint of their significance in the etiology of adultonset dietary obesity. Therefore, the present studies were undertaken to investigate the effect of different postnatal nutrition on the ontogeny of the small intestine in rats raised in small, normal and large litters and to establish whether the pre-existing biochemical and functional characteristics of the small intestine could be involved in the acceleration of obesity after receiving high fat/energy diet in later life.

\section{Methods}

Animals

Sprague-Dawley virgin rat dams (Charles River Laboratories, Prague) were mated at 10 weeks of age and individually housed in Plexiglas cages in a temperaturecontrolled environment of $22 \pm 2{ }^{\circ} \mathrm{C}$ with a relative humidity of $60 \pm 15 \%$ and a $12 \mathrm{~L}: 12 \mathrm{D}$ regime (light on 06:00-18:00 h). The mothers had free access to a standard laboratory diet (Laboratory diet M1, Prague; $3.2 \mathrm{kcal} / \mathrm{g}$, with $26.3 \%$ energy as protein, $9.5 \%$ as fat and $64.2 \%$ as carbohydrate) and tap water. To induce early postnatal overnutrition, normal nutrition and undernutrition in their progeny, the litter size was adjusted on the first day after birth to 4 pups/nest (small litters, SL), 10 pups/nest (normal litters, NL) and 16 pups/nest (large litters, LL). All groups contained males and females. To investigate the relationship between the litter size and milk composition, the milk samples of individual dams were collected on day 11 of lactation. To determine the somatic and intestinal parameters during lactation (on day 15) and on day 35 in SL, NL and LL groups eight male rats from each group were killed and body fat and small intestinal samples of proximal duodenum and middle part of the jejunum were taken. The remaining pups in SL, NL and LL groups on day 15 as well as the female rats on day 30 (after weaning) were excluded from the next experiments. The weaned male rats (day 30) from all three groups were housed in Plexiglass cages under the same conditions (diet, water, temperature, light-dark regime) as before weaning. On day 80, rats from SL, NL and LL were divided into two dietary groups: 1) control groups continued on a standard pellet diet for 8 weeks, 2) high energy (HE) groups (littermates of SL, NL and LL controls) were given the same standard diet ad libitum and, furthermore, were given access to a HE diet (Sunar- 
Heinz Products: milk-based liquid diet) containing 0.7 $\mathrm{kcal} / \mathrm{ml}$ with $17.5 \%$ energy content as protein (casein, whey protein), $30.0 \%$ as fat, $80 \%$ of which is milk fat, remaining linolic acid) and $55.5 \%$ as carbohydrate (lactose, fructose, oligofructose, maltodextrin) for 8 weeks. The intake of both diets in control and HE groups were monitored daily. The animals were killed at day 135 between 08:00 and 09:00 h. by decapitation with removal of epididymal plus retroperitoneal adipose depots and small intestinal segments. All animal work was in compliance with the Animal Ethics Committee of the Institute of Animal Physiology SAS, Košice.

\section{Milk composition}

The dams were milked on day 11 of lactation. The milk was obtained by a procedure described in detail previously (Mozeš et al.1993). Milk fat was determined by the crematocrit method of Lucas et al. (1978). Fat concentration was expressed in $\mathrm{g} / 100 \mathrm{ml}$ milk by the formula given by Nagasawa et al. (1989). Milk protein concentration was analyzed by the method of Lowry et al. (1951). The values were expressed in $\mathrm{g} / 100 \mathrm{ml}$ milk.

Enzyme assays and chemical analysis. For enzyme assay small $(0.5 \mathrm{~cm})$ segments were immediately removed, the lumen rinsed in distilled water, and frozen in hexane $\left(-70{ }^{\circ} \mathrm{C}\right)$. Segments of the frozen tissue (proximal duodenum and intermediate part of the jejunum) were cut $(8 \mu \mathrm{m})$ in a cryostat at $-25^{\circ} \mathrm{C}$ and the tissue slices were transferred onto glass slides and airdried.

The analysis of alkaline phosphatase activity was performed using a modified simultaneous azocoupling method (Lojda et al. 1979). The incubation medium contained $2.0 \mathrm{mM}$ naphthol AS-BI phosphate (Sigma, Deisenhofen, Germany), $0.8 \mathrm{mM}$ Hexazotized New fuchsin (Serva, Heidelberg, Germany), 20 mM N,Ndimethylformamide (solvent of naphtol AS-BI phosphate) and $0.05 \mathrm{M}$ veronal acetate buffer. The sections were incubated at $37{ }^{\circ} \mathrm{C}$ for $10 \mathrm{~min}$ at $\mathrm{pH} 8.9$ (Mozeš et al. 1998).

The histochemically stained slides were visualized at low magnification (objective $\mathrm{x} 4$ ) using Olympus microscope (BX 51) and digital compact camera (Olympus DP 50) connected with a host computer. Sections were illuminated with white light from a $12 \mathrm{~V}$ halogen lamp $(100 \mathrm{~W})$ after filtering with a $520 \mathrm{~nm}$ monochromatic filter.

Image analysis was performed by the Ellipse program (ViDiTo, Slovakia) where the gray level of each pixel was given by a value in the $0-255$ range. The correspondence between these gray level values and the known integrated absorbance values of the same section points was determined by calibration. To define the standard density values of enzyme activities at the wavelength of $520 \mathrm{~nm}$ (Frederiks et al. 1987) required for calibration, a Vickers M85a microdensitometer was used. A special semi-interactive algorithm was used to find relevant pixels along the villus length whose density was measured. This algorithm consists of several steps: a) filtering of the image by a Gaussian filter, resulting in a noise-free image without sharp density changes, b) threshold-based segmentation which separates dark areas from the image background, c) manual deleting of segmented dark areas that are not lying on a villus, d) skeletonization, where elongated dark areas along the villus are thinned into a skeleton curve e) optimization based on an active contour model algorithm where a skeleton curve searches for the darkest pixels in its neighborhood, which transforms the skeleton curve into a "ridge" curve connecting darkest pixels along the villus, f) density measurement of all pixels lying within a defined distance from the ridge curve. The quantification of the enzyme activity (pixel intensities) was carried out along the villus length in a whole section of at least four duodenal and jejunal slides and the mean values recorded were referred to one animal.

For chemical analysis, the mucosa from the defrosted tissue segments of duodenum and jejunum was scraped off with a glass microscope slide and weighed. The mucosal samples were homogenized in ice-cold PBS. The protein content was analyzed by the method of Lowry et al. (1951) using bovine serum albumin as the standard. DNA was evaluated by the fluorometric method (Koppel et al. 1981). Calf thymus DNA was used as the standard. Values are presented in $\mu \mathrm{g} / \mathrm{mg}$ mucosa of duodenum and jejunum.

\section{Statistical analysis}

Statistical analyses were carried out using the statistical package Statistica 6.1 (StatSoft CR, Prague, Czech Republic). Data were expressed as mean \pm S.E.M. and the statistical significance was accepted at the $\mathrm{P}<0.05$ level. Statistical evaluation of the developmental characteristics between pre- and post-weaning SL, NL and LL groups was carried out by one-way analysis of variance (ANOVA) and the post-hoc Fisher's LSD test was used to compare the differences between the groups at a given time point. Data from the assessment of the 

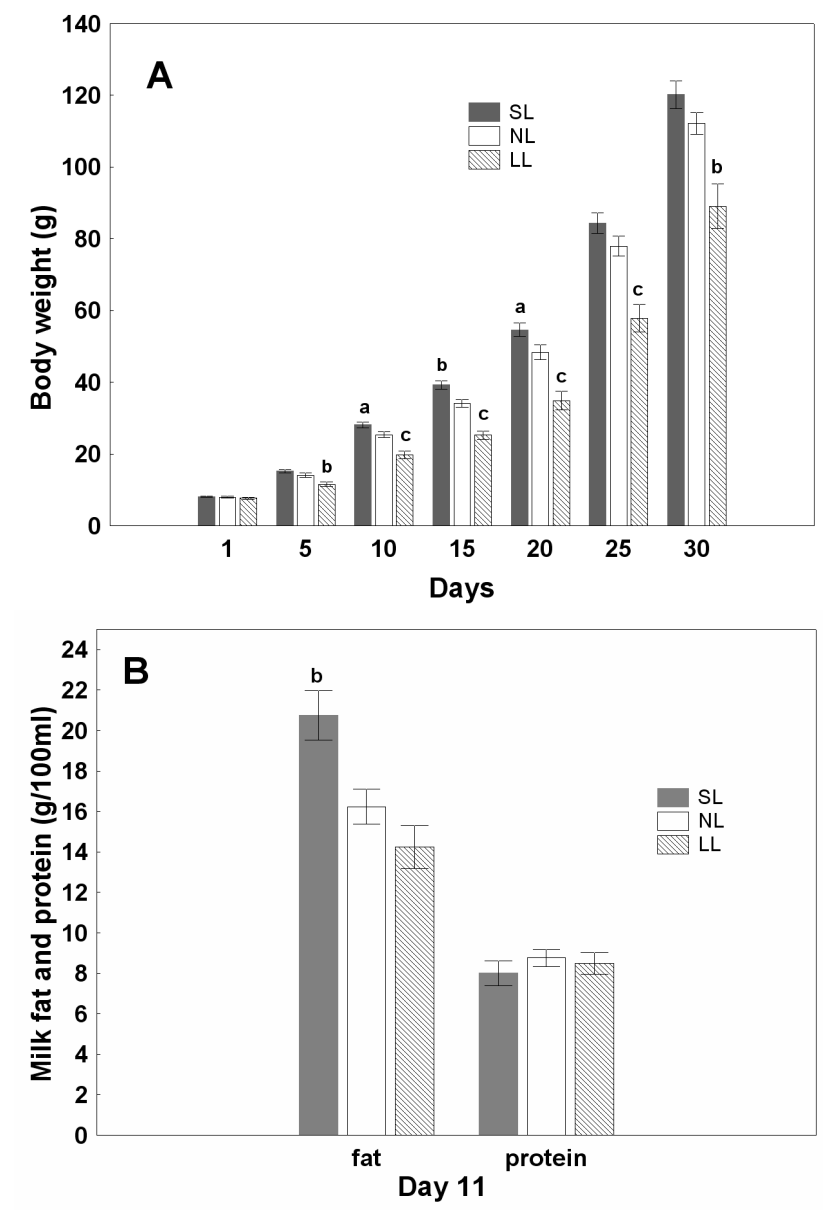

Fig. 1. A. Effect of litter size on body weight. Each value represents the means \pm S.E.M. of litter weight, the male pups reared in small litters (SL, 4 pups/nest), normal litters (NL 10 pups/nest) and large litters (LL, 16 pups/nest), respectively. B. Milk fat and protein concentration on postpartum day 11 in dams nursing small litters $(n=12)$, normal litters $(n=8)$ and large litters $(n=6)$. Significantly different from NL group a $P<0.05$, ${ }^{b} \mathrm{P}<0.01,{ }^{\mathrm{c}} \mathrm{P}<0.001$.

somatic and small intestinal responses to standard diet vs. HE diet in adult SL, NL and LL rats was analyzed using the 2 x 3 ANOVA with post-hoc Fisher's LSD test.

\section{Results}

Reduction of litter size resulted in a significant increase in milk fat concentration on postpartum day 11 in SL nursing dams, while the mean values of milk fat concentration in mothers nursing enlarged litters as compared with NL mothers were only slightly decreased. The concentration of milk protein during this time period did not differ between SL, LL and NL mothers (Fig. 1 B).

From day 10 until day 20 of age the overfed SL pups became heavier and the underfed LL pups from day 5 until weaning were significantly lighter than control NL rats (Fig. 1A). During the first half of the lactation period (day 1-15), SL pups displayed a significantly higher and LL rats a significantly lowered weight gain and body fat level (Table 1).

While these growth changes in SL offspring disappeared during the second period of lactation, their increased fat pad weight persisted until day 35. During this time period, the LL rats showed accelerated growth and in contrast with NL rats, there was no difference regarding the weight gain and body fat on day 35 among these groups (Table 2). From day 30 to day 35 the food intake expressed in $\mathrm{g}$ /day did not differ between these litter size groups, however, the LL rats consumed significantly more food relative to body weight when compared to the SL as well as to NL rats.

As compared with NL pups, reduced litter size in SL pups resulted in a significant increase in duodenal and jejunal alkaline phosphatase (AP) activity on day 15 . This significant difference also persisted in the later period (day 35). On the other hand, the development of augmented AP activity in postnatally undernourished LL rats was apparent on day 35, whereas in the earlier postnatal period, AP did not show any significant changes from NL controls.

Table 3 shows that body weight, body fat and food intake changes in SL and LL groups fed normal diet depended to some extent on their pre-weaning nutritional conditions. As compared to the NL controls raised in normal litters, SL offspring remained heavier and LL rats leaner $(\mathrm{P}<0.05)$, and the small-litter rats attained a final epididymal plus retroperitoneal fat pads weight that was $23 \%$ higher than the control values $(\mathrm{P}<0.05)$ and $32 \%$ higher than the large-litter values $(\mathrm{P}<0.01)$.

Long-term exposure to high fat (HF) diet significantly $(\mathrm{P}<0.001)$ increased the energy intake in all three groups. The body fat in postnatally overfed and underfed rats displayed a different susceptibility to this nutritional challenge. Comparison among standard diet receiving rats and their littermates on HF diet suggested that the body fat accretion was consistently higher (about $30 \%$ ) in SL and LL groups, whereas in NL rats this increase was $13 \%$ (Table 3). Litter size and diet significantly influenced both body fat and food intake while weight gain was influenced only by diet. A significant interaction, however, between liter size and diet $(\mathrm{P}<0.05)$ indicated that the contribution of dietary influences on weight gain variations depended on early nutritional experiences. 
Table 1. Body weight, weight gain, body fat and alkaline phosphatase (AP) activity of 15-days-old rats which were raised in litters of 4 $(\mathrm{SL}), 10(\mathrm{NL})$ and $16(\mathrm{LL})$, respectively.

\begin{tabular}{llll}
\hline & SL & NL & LL \\
\hline Body weight $(g)$ & $42.7 \pm 2.1^{\mathrm{c}}$ & $33.7 \pm 0.5$ & $21.4 \pm 0.5^{\mathrm{c}}$ \\
Weight gain $(1-15$ day) & $35.2 \pm 2.1^{\mathrm{c}}$ & $26.5 \pm 0.6$ & $13.9 \pm 0.6^{\mathrm{c}}$ \\
Fat $(\%$ b.w) & $0.50 \pm 0.03^{\mathrm{a}}$ & $0.42 \pm 0.02$ & $0.14 \pm 0.02^{\mathrm{c}}$ \\
AP activity in duodenum & $23.1 \pm 0,5^{\mathrm{b}}$ & $19.9 \pm 0.7$ & $19.4 \pm 0.6$ \\
AP activity in jejunum & $20.6 \pm 0.5^{\mathrm{a}}$ & $18.1 \pm 0.7$ & $19.2 \pm 0.8$
\end{tabular}

Table 2. Body weight, weight gain, body fat, food intake and alkaline phosphatase (AP) activity in 35-days-old rats which were raised in litters of $4(\mathrm{SL}), 10(\mathrm{NL})$ and $16(\mathrm{LL})$, respectively.

\begin{tabular}{llll}
\hline & SL & NL & LL \\
\hline Body weight (g) & $148.0 \pm 3.8$ & $152.2 \pm 4.5$ & $127.0 \pm 1.8^{\mathrm{c}}$ \\
Weight gain (20-35 day) & $107.8 \pm 2.9$ & $106.6 \pm 4.1$ & $101.5 \pm 1.2$ \\
Fat (\% b.w) & $1.0 \pm 0.09^{\mathrm{b}}$ & $0.7 \pm 0.03$ & $0.7 \pm 0.04$ \\
Food intake (g/day) & $17.6 \pm 0.5$ & $18.7 \pm 0.6$ & $17.2 \pm 0.6$ \\
Food intake (\% b.w) & $11.9 \pm 0.2$ & $12.3 \pm 0.3$ & $13.5 \pm 0.3^{\mathrm{c}}$ \\
AP activity in duodenum & $18.9 \pm 0.5^{\mathrm{b}}$ & $16.9 \pm 0.5$ & $20.2 \pm 0.3^{\mathrm{d}}$ \\
AP activity in jejunum & $18.0 \pm 0.7^{\mathrm{b}}$ & $15.8 \pm 0.7$ & $18.1 \pm 0.5^{\mathrm{b}}$ \\
\hline
\end{tabular}

Values are means \pm S.E.M. ( $n=8$ animals/groups). Body fat $(\%)$ represents epididymal plus retroperitoneal fat pads weight. The $24-$ hour food intake are means of five measurements (day 30-35) for each rat. AP activity is given as a density values (pixel intensities) in duodenal and jejunal enterocytes at wavelength of $520 \mathrm{~nm}$. Significantly different from NL group: ${ }^{\mathrm{a}} \mathrm{P}<0.05,{ }^{\mathrm{b}} \mathrm{P}<0.01,{ }^{\mathrm{c}} \mathrm{P}<0.001$, ${ }^{\mathrm{d}} \mathrm{P}<0.0001$ by LSD multiple comparison test after ANOVA.

Table 3. Body weight, body fat, food intake and alkaline phosphatase (AP) activity in postnatally overfed (SL), normally fed (NL) and underfed (LL) rats after 8 week exposure to normal diet (control groups) and HF/HE diet (experimental groups)

\begin{tabular}{|c|c|c|c|c|c|c|}
\hline & \multirow{2}{*}{$\begin{array}{l}\text { Body weight } \\
\text { (g) }\end{array}$} & \multirow{2}{*}{$\begin{array}{l}\text { Weight gain } \\
\text { (g) }\end{array}$} & \multirow{2}{*}{$\begin{array}{l}\text { Body fat } \\
\text { (\% b.w.) }\end{array}$} & \multirow{2}{*}{$\begin{array}{l}\text { Food intake } \\
\text { (kcal/day) }\end{array}$} & \multicolumn{2}{|c|}{ AP activity } \\
\hline & & & & & Duodenum & Jejunum \\
\hline \multicolumn{7}{|l|}{ Control diet } \\
\hline$S L$ & $580.0 \pm 19.7$ & $111.5 \pm 6.0$ & $3.4 \pm 0.3^{\mathrm{a}}$ & $102.4 \pm 3.8$ & $16.2 \pm 0.3^{\mathrm{c}}$ & $15.8 \pm 0.6^{\mathrm{c}}$ \\
\hline$N L$ & $542.4 \pm 9.3$ & $117.8 \pm 5.7$ & $2.6 \pm 0.2$ & $99.5 \pm 0.9$ & $13.4 \pm 0.7$ & $13.0 \pm 0.3$ \\
\hline$L L$ & $498.8 \pm 9.8^{\mathrm{a}}$ & $109.6 \pm 3.4$ & $2.3 \pm 0.1$ & $93.9 \pm 1.9$ & $15.7 \pm 0.3^{\mathrm{b}}$ & $15.8 \pm 0.1^{\mathrm{c}}$ \\
\hline \multicolumn{7}{|l|}{ HF/HE diet } \\
\hline$S L$ & $595.2 \pm 19.4^{\mathrm{a}}$ & $149.0 \pm 7.0^{\mathrm{a} * * *}$ & $4.7 \pm 0.5^{\mathrm{c} * *}$ & $128.9 \pm 2.1 * * * *$ & $15.3 \pm 0.5$ & $14.8 \pm 0.1$ \\
\hline$N L$ & $554.8 \pm 9.4$ & $126.2 \pm 7.2$ & $3.0 \pm 0.2$ & $125.7 \pm 1.5^{* * * *}$ & $15.2 \pm 0.6^{* *}$ & $16.0 \pm 0.3^{* * * *}$ \\
\hline$L L$ & $513.1 \pm 12.2^{\mathrm{a}}$ & $120.6 \pm 7.4$ & $3.3 \pm 0.3^{*}$ & $119.8 \pm 2.1 * * * *$ & $14.7 \pm 0.3$ & $15.6 \pm 0.6$ \\
\hline Litter size effect & $\mathrm{P}<0.0001$ & NS & $\mathrm{P}<0.001$ & $\mathrm{P}<0.01$ & $\mathrm{P}<0.05$ & $\mathrm{P}<0.05$ \\
\hline Diet effect & NS & $\mathrm{P}<0.01$ & $\mathrm{P}<0.001$ & $\mathrm{P}<0.0001$ & NS & NS \\
\hline $\begin{array}{l}\text { Litter size } x \\
\text { diet interaction }\end{array}$ & NS & $\mathrm{P}<0.05$ & NS & NS & $\mathrm{P}<0.01$ & $\mathrm{P}<0.001$ \\
\hline
\end{tabular}

Values are means \pm S.E.M. ( $n=8$ animals/groups). SL - small litters, 4 pups/nest, NL - normal litters, 10 pups/nest, LL - large litters, 16 pups/nest. Body fat (\%) represents epididymal plus retroperitoneal fat pads. AP activity is given as a density values (pixel intensities) in duodenal and jejunal enterocytes at wavelength of $520 \mathrm{~nm}$. Significantly different from NL group ${ }^{a} \mathrm{P}<0.05,{ }^{\mathrm{C}} \mathrm{P}<0.001$. Significant differences among control SL, NL, LL rats and their littermates receiving HF/HE diet. $* \mathrm{P}<0.05, * * \mathrm{P}<0.01, * * * \mathrm{P}<0.001$, $* * * * \mathrm{P}<0.0001$ by LSD multiple comparison test after two-way ANOVA. 
Total protein and DNA content did not differ between SL, NL and LL groups receiving the control diet (Figs 2A and 2B). HE diet significantly decreased the duodenal content in SL rats (by $34 \%$ ) and the jejunal DNA content (by $30 \%$ ) in LL rats and in the duodenum of the LL group a significant dietary and litter size $\mathrm{x}$ diet interaction could be identified (Fig. 2A). Due to these changes the protein/DNA ratio was significantly higher in the duodenum of SL rats ( $25 \%)$ and in the jejunum of LL rats (by $44 \%$ ), as compared with NL rats (Fig. 2C). Moreover, the significant litter size, dietary, and litter size $\mathrm{x}$ diet interaction $(\mathrm{P}<0.05)$ in the duodenum of the SL group as well as a significant dietary and litter size $\mathrm{x}$ diet interaction $(\mathrm{P}<0.05)$ in the jejunum of the LL group was found by $2 \times 3$ ANOVA.

Changes in intestinal activities of alkaline phosphatase (AP) in the SL, NL and LL controls and the HF diet rats are shown in Table 3. Comparison among litter sizes indicate that in rats receiving the control diet, AP activity was significantly greater $(20 \%)$ in both segments of the small intestine in SL and LL (20\%) than in NL rats. In contrast, exposure of these groups to HF diet elicited opposite adaptive changes for this enzyme, particularly in the NL group. Comparison among standard diet receiving rats and their littermates on HF diet revealed that AP activity was significantly raised by $13 \%$ in the duodenum and by $22 \%$ in the jejunum in NL rats, while the values of AP activity in rats from the SL and LL nests remained unchanged.

\section{Discussion}

Our results demonstrated that different levels of nutrition before weaning can induce permanent changes in body weight and body fat. This is in agreement with earlier research suggesting that the body weight of smalllitter males is higher and weight in large litter animals is lower in later life (Bassett and Craig 1988, Li et al. 2002). These data also show that overnutrition as a consequence of litter size reduction leads to early development of obesity, which these animals maintained lifelong, while in undernourished large litter rats, their preweaning deficit in body fat was thereafter reduced and in adulthood their body fat weight did not significantly differed from the NL group (Bassett and Craig 1988, Fiorotto et al. 1991, Plagemann et al. 1992). Concerning the effect of early nutritional experience on feeding behavior, some evidence has been provided that the food intake did not differ among juvenile SL and NL rats
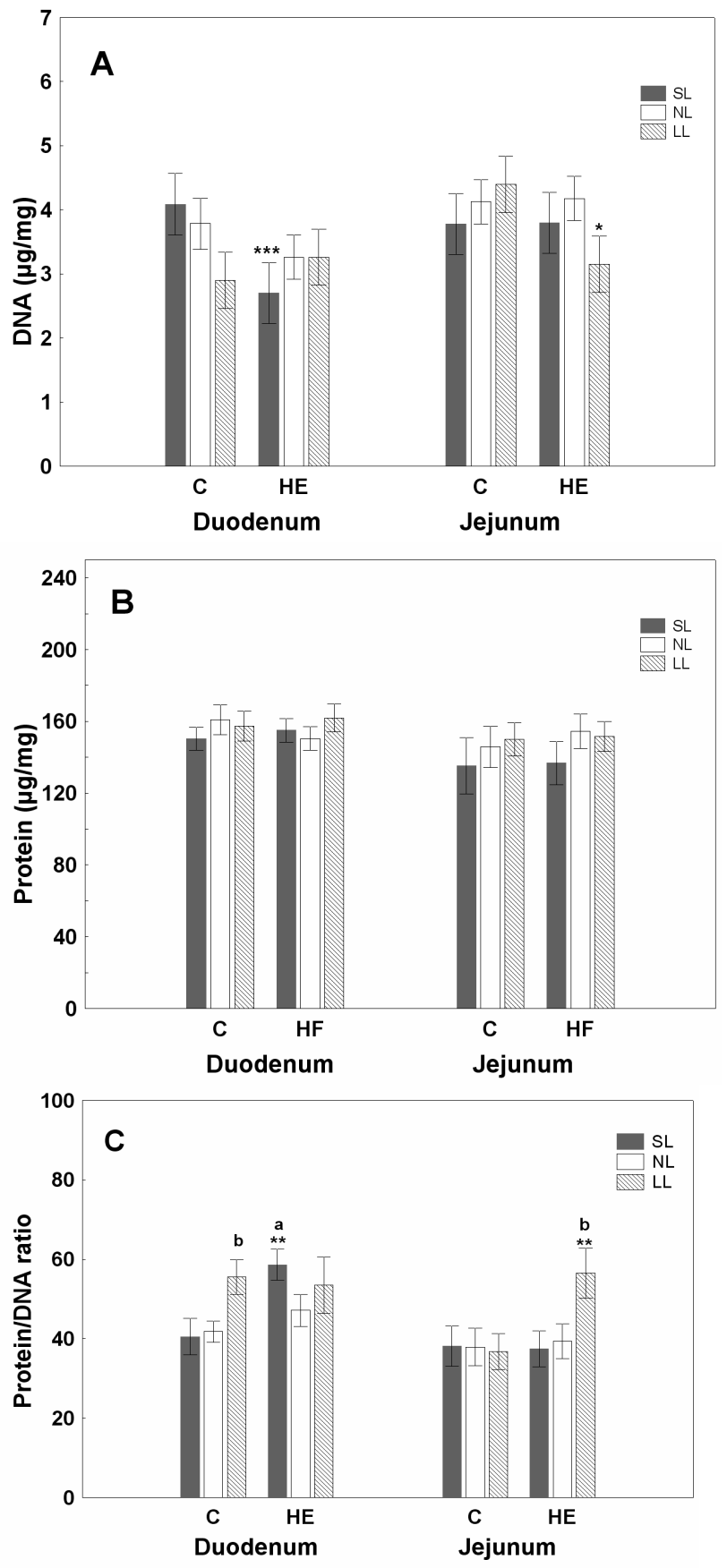

Fig. 2. Diet-related changes of DNA (A), protein (B) and protein/DNA ratio (C) in duodenal and jejunal mucosal tissues of adult male offspring reared in small litters (SL), normal litters (NL) and large litters (LL) fed either a control or a high energy diet. Values are means \pm S.E.M. Significantly different from NL group a $\mathrm{P}<0.05,{ }^{\text {b }} \mathrm{P}<0.01$. Significant differences among control $\mathrm{SL}, \mathrm{NL}$ and $\mathrm{LL}$ rats and their littermates receiving $\mathrm{HE}$ diet. $* \mathrm{P}<0.05, * * \mathrm{P}<0.01, * * * \mathrm{P}<0.001$. Data analyzed by two-way ANOVA, A: duodenum - dietary effect $P<0.05$, litter size $x$ diet interaction $P<0.05$. C: duodenum-litter size, diet and litter size $x$ diet interaction $P<0.05$, jejunum - dietary effect $P<0.05$, litter size $\mathrm{x}$ diet interaction $\mathrm{P}<0.05$.

(Mozeš et al. 2004) and the previous malnutrition in LL pups during lactation was normalized in the later period 
of life (Plagemann et al. 1992). This is in agreement with our results suggesting nearly the same food intake of obese SL and lean NL and LL rats in adulthood.

A similar responsiveness in the food intake has been observed when the animals were exposed to a HF diet, i.e. the results failed to reveal any significant differences in food consumption between SL, NL and LL groups. These results also suggested that hyperphagia after long-term HF diet consumption may per se lead to the accretion of fat depots, however, some differences, particularly among NL and both SL and LL groups do exist. While the HF diet feeding alone sufficed to induce the elevation of weight gain and weight of fat pads (as compared to their control littermates) in all groups, SL and LL rats were more susceptible to this dietary challenge and displayed a more prominent increase in body fat parameters. This indicates that the amplification of body fat enlargement after HF diet consumption in SL and LL rats might be a critical consequence of previously acquired disturbances in energy homeostasis and that besides the increased appetite, other factors may also contribute to modulation of their adiposity.

Our results showed that the postnatal over- or undernutrition has long-term consequences on the small intestine biochemical and functional properties, which was confirmed by a significant elevation of intestinal protein/DNA ratio and AP activity in later life when these animals were exposed to a high fat diet. Due to the fact that the food intake between SL and LL rats did not differ in adulthood, these changes might rather be explained by previously acquired nutritional imprint on small intestine maturation. It has been demonstrated that the malnutrition imposed during preweaning period resulted in an elevated mucosal protein/DNA ratio in post-weaning period and young rats (Jonas et al. 1991, Lin et al. 1998). From developmental aspect the activity of AP in the small intestine substantially increased from day 12 to day 24 (Yeh et al. 1994 ) when a gradual replacement of milk by solid food diet occurred and decreased thereafter in following periods of life (Tojyo 1984, Bernard et al. 1992). In addition, the early overnutrition resulted in their long-lasting increase (Mozeš et al. 2004). In the light of present knowledge it is feasible to assume that in SL and LL rats the abundance of nutrients that occur at different periods of early life may elicit a functionally parallel adaptation and overcompensation of enzyme activity. An indication of this is the fact that the higher activity of enzymes in these groups is fixed for later life, i.e. at the time when their increased food intake disappeared and when the time course of these changes did not correspond to an observed natural decrease of AP activity that occurs in normally developing NL rats.

However, it still remains to be elucidated what is the relationship between the increased AP activity in small intestine and the altered body fat regulation in SL and LL animals. It was found that the obesity in laboratory rodents is accompanied with a substantially elevated of brush-border-bound AP activity (Ramaswamy and Flint 1980, Mozeš et al. 2000, 2004). Nevertheless, the significance of their disordered expression on body fat accretion is not fully understood. For instance, it was reported that the increase in AP activity may precede the development of obesity observed at later periods of life (Mozeš et al. 2000) and there also exists evidence indicating the inverse relation between intestinal AP and the rate of fat absorption in obese animals. Consistently, in AP deficient $\mathrm{KO}$ mice after long-time exposure to a HF diet, a faster body weight gain, elevation of serum triglyceride levels and accelerated transport of fat droplets in comparison with wild-type controls has been observed (Narisawa et al. 2003). In this regard, our data indicated the possibility of an inverse relationship between intestinal AP activity and body fat. Indeed, we found that long-term feeding of the HF diet significantly increased AP activity in NL rats, whereas their adiposity was enlarged to a lesser extent. In contrast, this enzyme activity in SL and LL rats did not increase, but this adaptation deficit was accompanied by a significant body fat depots enlargement in these animals. However, with regard to the presented data, a further detailed study will be needed to clarify whether the better effectiveness of nutrient absorption, the absence of additional increase of AP activity or both are of importance for the maintenance of elevated body fat weight in SL and LL rats.

One potentially interesting aspect of the present results is that the early postnatal over- or undernutrition could represent a predisposing factor for the permanent increase of brush-border-bound duodenal and jejunal AP activity. Nevertheless, the acquired small intestinal plasticity can also be changed by late nutritional conditions when caloric density of the diet is raised and might be involved in lifelong persisting disturbances of body fat regulation. From this point of view the present findings extend our knowledge of the effect of inappropriate nutrition in early life, and allow better understanding of the intestinal mechanisms that may limit or prevent the obesity risk in later life. Since human obesity is not homogeneous regarding its genetic and 
nutritional background, further studies are necessary to determine the involvement of nutritional imprint on small intestine maturation, obesity development and expression of susceptibility or resistance to the high-energy diet. It can provide a benefit for both prevention and obesity treatment particularly in the majority of obesity prone individuals in which pharmacological interventions and dietary restriction have no permanent effect on body weight and body fat reduction.

\section{Acknowledgements}

We thank Dr. T. Hájek and Dr. L. Raček for expert technical assistance. This work was supported by grant 2/5141/25 of the Slovak Academy of Sciences and by EU project QLK 1-2000-00515 / QLRT-2002-02793.

\section{References}

ARMSTRONG J, DOROSTY AR, REILLY JJ, EMMETT PM: Coexistence of social inequalities in undernutrition and obesity in preschool children: population based cross sectional study. Arch Dis Child 88: 671-675, 2003.

BASSETT DR, CRAIG BW: Influence of early nutrition on growth and adipose tissue characteristics in male and female rats. J Appl Physiol 64: 1249-1256, 1988.

BERNARD A, CASELLI C, BLOND JP, CARLIER H: Diet fatty acid composition, age and rat jejunal microvillus enzyme activities. Comp Biochem Physiol A 101: 607-612, 1992.

ESTORNELL E, CABO J, BARBER T: Protein synthesis is stimulated in nutritionally obese rats. J Nutr 125: 1309$1315,1995$.

FIOROTTO ML, BURRIN DG, PEREZ M, REEDS PJ: Intake and use of milk nutrients by rat pups suckled in small, medium, or large litters. Am J Physiol 260: R1104-R1113, 1991.

FREDERIKS WM, MARX F, JONGES GN, VAN NOORDEN CJF: Quantitative histochemical study of acid phosphatase activity in rat liver using a semipermeable membrane technique. J Histochem Cytochem 35: 175$180,1987$.

GHAFOORUNISSA SA: Influence of dietary partially hydrogenated fat high in trans fatty acids on lipid composition and function of intestinal brush border membrane in rats. J Nutr Biochem 12: 116-120, 2001.

HODIN RA, CHAMBERLAIN SM, MENG S: Pattern of rat intestinal brush-border enzyme gene expression changes with epithelial growth state. Am J Physiol 269: C385-C391, 1995.

JONAS A, DIVER-HABER A, YAHAV J: Adaptive response of ileal mucosa to malnutrition in the rat: role of polyamines. Acta Physiol Scand 142: 387-395, 1991.

KAIN J, VIO F, ALBALA C: Obesity trends and determinant factors in Latin America. Cad Saude Publica 19 (Suppl 1): S77-S86, 2003.

KALIES H, HEINRICH J, BORTE N, SCHAAF B, VON BERG A, VON KRIES R, WICHMANN HE, BOLTE G; LISA STUDY GROUP: The effect of breastfeeding on weight gain in infants: results of a birth cohort study. Eur J Med Res 10: 36-42, 2005.

KAUR M, KAUR J, OJHA S, MAHMOOD A: Dietary fat effects on brush border membrane composition and enzyme activities in rat intestine. Ann Nutr Metab 40: 269-276, 1996.

KOPPEL J, KUCHÁR S, MOZEŠ Š, BOĎA K: Nucleic acids content of some fetal and neonatal rat organs after insulin treatment. Endokrinologie 77: 95-100, 1981.

KOZAK R, RICHY S, BECK B: Persistent alterations in neuropeptide Y release in the par a ventricular nucleus of rats subjected to dietary manipulation during early life. Eur J Neurosci 21: 2887-2892, 2005.

LEONHARDT M, LESAGE J, CROIX D, DUTRIEZ-CASTELOOT I, BEAUVILLAIN JC, DUPOUY JP: Effects of perinatal maternal food restriction on pituitary-gonadal axis and plasma leptin level in rat pup at birth and weaning and on timing of puberty. Biol Reprod 68: 390-400, 2003.

LI Y, PLAGEMANN A, DAVIDOWA H: Increased inhibition by agouti-related peptide of ventromedial hypothalamic neurons in rats overweight due to early postnatal overfeeding. Neurosci Lett 330: 33-36, 2002.

LIN CH, CORREIA L, TOLIA K, GESELL MS, TOLIA V, LEE PC, LUK GD: Early weaning induces jejunal ornithine decarboxylase and cell proliferation in neonatal rats. J Nutr 128: 1636-1642, 1998. 
LOJDA Z, GOSSRAU R, AND SCHIBLER TH: Enzyme Histochemistry. Springer, Berlin, 1979, pp 59-70.

LOWRY OH, ROSENBROUGH NJ, FARR AL, RANDALL RR: Protein measurement with the Folin phenol reagent. J Biol Chem 193: 265-275, 1951.

LUCAS A, GIBBS JH, LYSTER RL, BAUM JD: Crematocrit: simple clinical technique for estimating fat concentration and energy value of human milk. Brit Med J 1: 1018-1020, 1978.

MAHMOOD A, SHAO JS, ALPERS DH: Rat enterocytes secrete SLPs containing alkaline phosphatase and cubilin in response to corn oil feeding. Am J Physiol 285: G433-G441, 2003.

MOZEŠ Š, KUCHÁR S, RYBOŠOVÁ Z, NOVÁKOVÁ V: Milk fat concentration and growth of rat pups. Physiol Res 42: 29-33, 1993.

MOZEŠ Š, LENHARDT L', MARTINKOVÁ A: A quantitative histochemical study of alkaline phosphatase activity in isolated rat duodenal epithelial cells. Histochem J 30: 1-7, 1998.

MOZEŠ Š, LENHARDT L, MARTINKOVÁ A: Alkaline phosphatase activity of duodenal enterocytes after neonatal administration of monosodium glutamate to rats. Physiol Res 49: 269-277, 2000.

MOZEŠ Š, ŠEFČÍKOVÁ Z, LENHARDT L, RAČEK L: Obesity and changes of alkaline phosphatase activity in the small intestine of 40- and 80-day-old rats subjected to early postnatal overfeeding or monosodium glutamate. Physiol Res 53: 177-186, 2004.

NAGASAWA H, NAITO T, KATAOKA K: Relationship between milk composition and pup's growth in mice. Proc Soc Exp Biol Med 191: 78-81, 1989.

NARISAWA S, HUANG L, IWASAKI A, HASEGAWA H, ALPERS DH, LUIS MILLÁN JL: Accelerated fat absorption in intestinal alkaline phosphatase knockout mice. Mol Cell Biol 23: 7525-7530, 2003.

PASSOS MC, VICENTE LL, LISBOA PC, DE MOURA EG: Absence of anorectic effect to acute peripheral leptin treatment in adult rats whose mothers were malnourished during lactation. Horm Metab Res 36: 625-629, 2004.

PATHAK RM, MAHMOOD A, DUDEJA PK, SUBRAHMANYAM D: Intestinal brush border membrane structure and function: effect of early postnatal undernutrition. Pediatr Res 15: 112-114, 1981.

PLAGEMANN A, HEIDRICH I, GOTZ F, ROHDE W, DORNER G: Obesity and enhanced diabetes and cardiovascular risk in adult rats due to early postnatal overfeeding. Exp Clin Endocrinol 99: 154-158. 1992.

PLAGEMANN A, HARDER T, RAKE A, VOITS M, FINK H, ROHDE W, DORNER G: Perinatal elevation of hypothalamic insulin, acquired malformation of hypothalamic galaninergic neurons, and syndrome $\mathrm{x}$-like alterations in adulthood of neonatally overfed rats. Brain Res 836: 146-155, 1999.

RAMASWAMY K, FLINT PW: Effect of genetic diabetes on enzymes of mouse intestinal brush-border membrane. Am J Physiol 238: G114-G118, 1980.

STUBBS RJ, HUGHES DA, JOHNSTONE AM, HORGAN GW, KING N, BLUNDELL JE: A decrease in physical activity affects appetite, energy, and nutrient balance in lean men feeding ad libitum. Am J Clin Nutr 79: 62-69, 2004.

TEIXEIRA CV, PASSOS MC, RAMOS CD, DUTRA SC, DE MOURA EG: Leptin serum concentration, food intake and body weight in rats whose mothers were exposed to malnutrition during lactation. J Nutr Biochem 13: 493498, 2002.

TOJYO Y: Developmental changeover in rat duodenal alkaline phosphatase. Comp Biochem Physiol B 77: 437-441, 1984.

VICKERS MH, BREIER BH, CUTFIELD WS, HOFMAN PL, GLUCKMAN PD: Fetal origins of hyperphagia, obesity, and hypertension and postnatal amplification by hypercaloric nutrition. Am J Physiol 279: E83-E87, 2000.

VICKERS MH, BREIER BH, MCCARTHY D, GLUCKMAN PD: Sedentary behavior during postnatal life is determined by the prenatal environment and exacerbated by postnatal hypercaloric nutrition. Am J Physiol $\mathbf{2 8 5}$ : R271-R273, 2003.

YEH K, YEH M, HOLT PR, ALPERS DH: Development and hormonal modulation of postnatal expression of intestinal alkaline phosphatase mRNA species and their encoded isoenzymes. Biochem J 301: 893-899, 1994. 
ZHANG Y, SHAO JS, XIE QM, ALPERS DH: Immunolocalization of alkaline phosphatase and surfactant-like particle proteins in rat duodenum during fat absorption. Gastroenterology 110: 478-488, 1996.

\section{Corresponding author}

Š. Mozeš, Institute of Animal Physiology, Slovak Academy of Sciences, Šoltésovej 4, 040 01, Košice. Slovak Republic. Fax: +421 55 7287842. E-mail: mozes@saske.sk 